\title{
Percutaneous absorption of 2-butoxyethanol vapour in human subjects
}

\author{
Gunnar Johanson, Anders Boman
}

Abstract

Four male volunteers were exposed at rest for two periods of two hours, separated by a one hour exposure free interval, to $50 \mathrm{ppm}$ 2-butoxyethanol (BE) vapour generated in an exposure chamber. During the first two hour period the men were exposed by mouth only via a respiratory valve connected by tubes to the exposure chamber. During the second exposure period the men were exposed by skin only while sitting inside the exposure chamber, naked except for shorts, and wearing a respiratory protection mask supplied with compressed air. Capillary blood samples were collected at regular intervals and analysed for BE by a gas chromatographic method. Two experiments separated by at least two weeks were carried out with each volunteer, one at "normal" ( $23^{\circ} \mathrm{C}, 29 \%$ relative humidity) and one at raised $\left(33^{\circ} \mathrm{C}, 71 \%\right.$ relative humidity) air temperature and humidity in the chamber. The average concentration in blood and the calculated rate of uptake of $B E$ were about three to four times higher during dermal exposure than during inhalation exposure. These experiments suggest that dermal uptake of $\mathrm{BE}$ accounts for about $75 \%(45-85 \%$ in individual experiments) of the total uptake during whole body exposure to $B E$ vapour. Thus it appears that the use of a respiratory protection mask will not protect efficiently against exposure to $B E$ vapours. $A$ tendency towards increased percutaneous absorption rate was seen in the raised temperature and humidity condition.

Division of Work and Environmental Physiology, National Institute of Occupational Health, Solna, Sweden and Department of Occupational Medicine, University Hospital, Uppsala, Sweden

G Johanson

Division of Occupational Dermatology, National Institute of Occupational Health, Solna, Sweden A Boman
Ethylene glycol monoalkyl ethers are commonly used as solvents in products such as paints, lacquers, and cleansing agents. The glycol ethers are readily absorbed by the human body. Respiratory uptake has been shown for 2-butoxyethanol (BE), ${ }^{1}$ 2-ethoxyethanol, ${ }^{2}$ and 2-methoxyethanol ${ }^{3}$ vapours. Also undiluted BE, 2-ethoxyethanol, 2-methoxyethanol, 1-methoxy2-propanol, and other glycol ethers are readily absorbed across human skin in vitro. ${ }^{4}$ Percutaneous absorption of undiluted BE has also been demonstrated in human subjects in vivo. ${ }^{5}$ We found no publications on dermal uptake of glycol ether vapours.

The aim of the present study was to determine the percutaneous absorption of $\mathrm{BE}$ vapour in human subjects, and to quantitatively compare it with the respiratory uptake. The uptake rates were calculated from measured concentrations of $\mathrm{BE}$ in blood.

Materials and methods

SUBJECTS

Four men (age range $23-36$, body weight $75-80 \mathrm{~kg}$, body length $178-187 \mathrm{~cm}$ ) participated in the experiment. The men were in good health as indicated by the answers to a questionnaire, a medical examination, and analysis of blood. All four were without history of serious diseases and had a normal appearance of the skin, with some minor exceptions: one had a small lesion (area $5 \mathrm{~cm}^{2}$ ) on his right knee with a suspicion of psoriasis, one had mild acne on his back, and one had a pigmented spot on his chest as a result of sun damage eight years earlier. One had a history of childhood atopic dermatitis, but this had cleared several years before the present investigation. None of the men were taking medicines at the time of the experiments. One subject smoked around five cigarettes a day; the other three were non-smokers. The alcohol consumption of the subjects corresponded to one bottle of wine or less a week.

The subjects were instructed not to drink any alcoholic beverages 48 hours before and during the experiment.

The four men volunteered for the experiments. They were informed by verbal as well as written instructions about the design of the study and possible hazards and that they were free to desist at 
any time. The experiments were approved by the ethical committee at the Karolinska Institute, Stockholm.

\section{EXPOSURE CONDITIONS}

The $\mathrm{BE}$ vapour was generated and maintained at 2 $\mathrm{mmol} / \mathrm{m}^{3}(50 \mathrm{ppm})$ in an exposure chamber. To minimise leakage of $\mathrm{BE}$ the air pressure was kept slightly lower in the chamber than in the surrounding laboratory. The exposure chamber is described in more detail elsewhere. ${ }^{1}$ Two subjects were exposed in each experiment. An experiment consisted of two two hour exposures to chamber air separated by one hour of no exposure. The first exposure period occurred between 900 and 1100 . The subjects were breathing chamber air while sitting in a comfortable armchair outside the exposure chamber. The mouth valve was connected to the chamber via separate tubes for inhalation and exhalation. Mouth breathing was assured by the use of a nose clip. No BE was detected outside the chamber; thus exposure to $\mathrm{BE}$ occurred via inhalation only. Pulmonary ventilation was recorded with a Wright spirometer. Between the two exposures (1100-1200) the subjects ate lunch. The second exposure period occurred between 1200 and 1400 . This time the subjects were sitting inside the exposure chamber dressed in shorts only and equipped with a close fitting respiratory protection mask (Spiromatic, Interspiro AB, Lidingö, Sweden or Panorama Nova, Dräger, Lübeck, Germany) connected to a lung governed positive pressure respirator. The breathing air was supplied from a tank with pressurised clean air (andningsluft, AGA $\mathrm{AB}$, Älvsjö, Sweden). Leakage of BE into the mask was not indicated by smell at any time. Immediately after the two hour skin exposure the subjects took a shower. Heart rate was monitored during the entire day by electrocardiogram telemetry (Sport Tester PE-3000, Polar Electro Oy, Kempele, Finland). Each volunteer participated in two experiments, one at "normal" $\left(23^{\circ} \mathrm{C}, 29 \%\right.$ relative humidity) and one at raised temperature and humidity $\left(33^{\circ} \mathrm{C}, 71 \%\right)$ conditions (table 1). The two experiments were separated by two weeks or more.

\section{BLOOD ANALYSIS}

Duplicate capillary blood samples of $200 \mu \mathrm{l}$ were collected at regular intervals before, during, and after the exposures. Immediately before sampling, the subject immersed his hand for about 30 seconds in a beaker filled with freshly prepared warm water $\left(40^{\circ} \mathrm{C}\right)$. This procedure, which was performed twice, served two purposes: (1) to wash off any BE that might have been absorbed on the skin surface during exposure, and (2) to "arterialise" the capillary blood in the fingers by vasodilatation. To avoid contamination by BE the blood was sampled inside a transparent glove box flushed with clean air. When inside the exposure chamber the subjects kept the left arm through a hole in the chamber wall during blood sampling. The blood samples were treated with pentafluorobenzoyl chloride and analysed by gas

Table 1 Exposure conditions, physiological measurements, and 2-butoxyethanol (BE) toxicokinetics. Ranges in individual experiments are given in parentheses

\begin{tabular}{|c|c|c|c|c|}
\hline & \multicolumn{2}{|c|}{ "Normal" temperature and humidity } & \multicolumn{2}{|c|}{ Raised temperature and humidity } \\
\hline & Mean & $(\min -\max )$ & Mean & $(\min -\max )$ \\
\hline \multicolumn{5}{|c|}{ Exposure conditions } \\
\hline $\begin{array}{l}\text { Chamber temperature }\left({ }^{\circ} \mathrm{C}\right) \\
\text { Relative humidity in chamber air }(\%) \\
\text { BE in chamber air }\left(\mathrm{mmol} / \mathrm{m}^{3}\right) \text { : }\end{array}$ & $\begin{array}{l}22 \cdot 6 \\
29\end{array}$ & $\begin{array}{l}(22-24) \\
(20-38)\end{array}$ & $\begin{array}{l}32 \cdot 9 \\
71\end{array}$ & $\begin{array}{r}\cdot(31-36) \\
(55-82)\end{array}$ \\
\hline $\begin{array}{l}\text { During mouth exposure } \\
\text { During skin exposure }\end{array}$ & $\begin{array}{l}2 \cdot 08 \\
2 \cdot 05\end{array}$ & $\begin{array}{l}(2 \cdot 08-2 \cdot 08) \\
(2 \cdot 04-2 \cdot 05)\end{array}$ & $\begin{array}{l}2 \cdot 02 \\
2 \cdot 08\end{array}$ & $\begin{array}{l}(2 \cdot 02-2 \cdot 02) \\
(2 \cdot 07-2 \cdot 09)\end{array}$ \\
\hline Pulmonary ventilation $(1 / \mathrm{min})$ & \multicolumn{4}{|c|}{ Physiological measurements } \\
\hline $\begin{array}{l}\text { Heart rate }\left(\min ^{-1}\right) \text { : } \\
\text { During mouth exposure } \\
\text { During skin exposure }\end{array}$ & $\begin{array}{l}64 \\
65\end{array}$ & $\begin{array}{l}(59-67) \\
(57-74)\end{array}$ & $\begin{array}{l}62 \\
70\end{array}$ & $\begin{array}{l}(52-72) \\
(59-76)\end{array}$ \\
\hline \multicolumn{5}{|c|}{ BE toxicokinetics } \\
\hline $\begin{array}{l}\text { Concentration in blood }(\mu \mathrm{mol} / 1):^{\star} \\
\text { During mouth exposure } \\
\text { During skin exposure } \\
\text { Skin:mouth ratio }\end{array}$ & $\begin{array}{l}2 \cdot 4 \\
6 \cdot 3 \\
2 \cdot 9\end{array}$ & $\begin{array}{l}(1 \cdot 8-2 \cdot 7) \\
(1 \cdot 8-9 \cdot 8) \\
(0 \cdot 7-5 \cdot 5)\end{array}$ & $\begin{array}{l}3 \cdot 4 \\
12 \\
3 \cdot 5\end{array}$ & $\begin{array}{l}(2 \cdot 8-4 \cdot 0) \\
(10-13) \\
(2 \cdot 7-4 \cdot 4)\end{array}$ \\
\hline $\begin{array}{l}\text { Uptake rate ( } \mu \mathrm{mol} / \mathrm{min}): \dagger \\
\text { During mouth exposure } \\
\text { During skin exposure } \\
\quad \text { Skin:mouth ratio } \\
\text { Contribution of dermal uptake to total uptake (\%) } \\
\text { Apparent blood clearance }(1 / \mathrm{min}) \\
\text { Half life in blood (min) }\end{array}$ & $\begin{array}{l}9 \cdot 9 \\
32 \\
3 \cdot 4 \\
71 \\
4 \cdot 1 \\
36\end{array}$ & $\begin{array}{l}(8 \cdot 3-11) \\
(8 \cdot 7-49) \\
(0 \cdot 8-5 \cdot 9) \\
(45-85) \\
(3 \cdot 5-4 \cdot 8) \\
(19-53)\end{array}$ & $\begin{array}{c}11 \cdot 4 \\
44 \\
4 \cdot 1 \\
79 \\
3 \cdot 4 \\
32\end{array}$ & $\begin{array}{l}(8 \cdot 9-14) \\
(40-49) \\
(2 \cdot 8-4 \cdot 8) \\
(74-83) \\
(3 \cdot 3-3 \cdot 6) \\
(23-39)\end{array}$ \\
\hline
\end{tabular}

*Average during second hour of exposure.

$\dagger$ Normalised to an exposure concentration of $2.00 \mathrm{mmol} / \mathrm{m}^{3}$. 
chromatography with electron capture detection as described elsewhere. ${ }^{1}$ All samples were treated and analysed in duplicate.

\section{CALCULATIONS}

The respiratory uptake rate was calculated as the product of the concentration of $B E$ in inhaled air, the pulmonary ventilation, and the relative respiratory uptake. Based on earlier observations, ${ }^{1}$ the relative uptake of BE was assumed to be $60 \%$. The apparent blood clearance of BE (CL) was calculated as the respiratory uptake divided by the area under the blood BE concentration time curve of mouth exposure $\left(\mathrm{AUC}_{\text {mouth }}\right)$. The $\mathrm{AUC}_{\text {mouth }}$ was calculated by the trapezoidal rule from 0 to two hours with the addition of a rest term to account for extrapolation to infinity. The rest term was determined as the concentration at two hours divided by the elimination rate constant. The elimination rate constant and half life of $\mathrm{BE}$ in blood were calculated by log linear regression analysis on the concentrations measured at five to seven hours, assuming first order monoexponential decay.

The percutaneous absorption was calculated as the product of $\mathrm{CL}$ and the AUC of skin exposure $\left(A U C_{\text {skin }}\right)$. The $\mathrm{AUC}_{\text {skin }}$ was obtained by the trapezoidal method from three to seven hours with the addition of a rest term-namely, the concentration at seven hours divided by the slope constant, to account for extrapolation to infinity.

The concentration of $\mathrm{BE}$ in chamber air differed by a few per cent between experiments. All uptake rates were therefore corrected to a nominal BE concentration in air of $2.00 \mathrm{mmol} / \mathrm{m}^{3}$.

The permeability coefficient was calculated as percutaneous absorption rate divided by body surface area. This area was obtained from the formula: $71.84 \times$ body weight ${ }^{0.425} \times$ length $^{0.725}$ as given by Dubois and Dubois. ${ }^{6}$ Statistical comparisons were made with Student's $t$ test (two tailed, paired observations). Arithmetic averages, and ranges in individual experiments within parentheses, are given unless otherwise stated.

\section{Results}

\section{MOUTH EXPOSURE}

The concentration of $\mathrm{BE}$ in blood increased during the first hour of mouth exposure and appeared to approach a steady state at about $3 \mu \mathrm{M}(1 \cdot 8-4 \cdot 0 \mu \mathrm{M}$ in the individual experiments) during the second hour (figure and table 1 ). The respiratory uptake was 1.3 $(1.0-1 \cdot 7) \mathrm{mmol}$ or $11(8 \cdot 3-14) \mu \mathrm{mol} / \mathrm{min}$ and the apparent blood clearance $3 \cdot 8(3 \cdot 3-4 \cdot 8) \mathrm{l} / \mathrm{min}$.

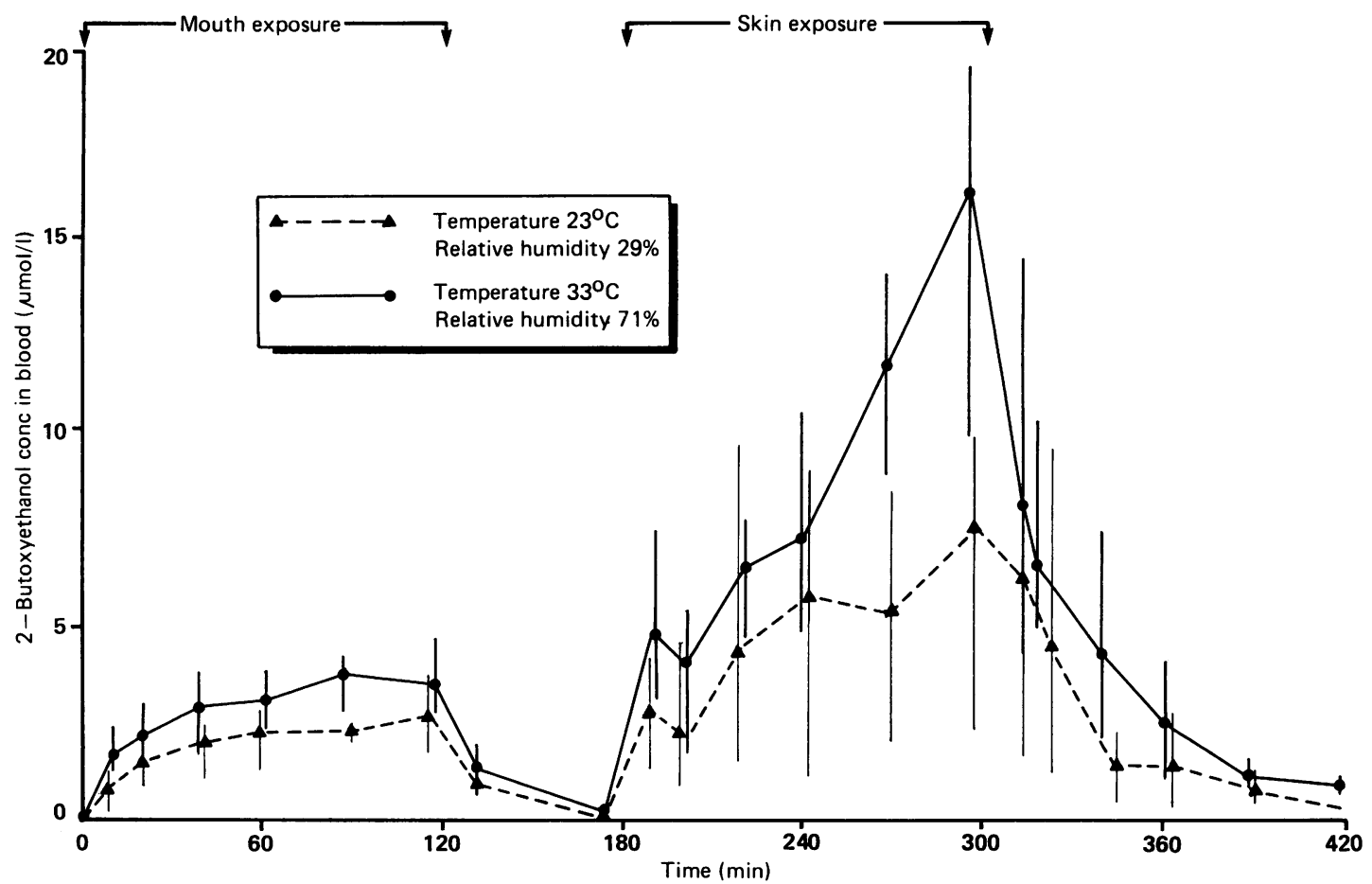

Time course of average concentration of 2-butoxyethanol in blood from four men exposed to $2 \mathrm{mmol} / \mathrm{m}^{3}$ ( $\left.50 \mathrm{ppm}\right)$ 2-butoxyethanol vapour by mouth only (0-120 minutes) and by skin only (180-300 minutes) at "normal" and raised air temperature and humidity conditions. Vertical bars indicate the range of observations in individual experiments. 
PERCUTANEOUS EXPOSURE

The concentration of $\mathrm{BE}$ in blood increased to about $9(1 \cdot 8-13) \mu \mathrm{M}$ during the second hour of skin exposure. In seven of the experiments the BE blood concentration was 2.4-5.5 times higher after skin exposure than after mouth exposure; in one it was lower. This difference was also reflected in the high percutaneous absorption of $31(8 \cdot 6-48) \mu \mathrm{mol} / \mathrm{min}$, or $2 \cdot 5-5 \cdot 9$ times higher than the respiratory uptake. The differences between mouth and skin exposure were statistically significant with respect to measured $\mathrm{BE}$ blood concentrations as well as calculated uptake rates ( $\mathrm{p}=0.0018$ and $\mathrm{p}=0.0034$ respectively).

The half life of BE in blood after the skin exposure averaged 34 minutes with an individual range of 1953 minutes.

Only small and inconsistent differences in heart rates were found between the two routes of exposure (table 1). Thus the observed differences in blood concentrations and uptake rates of $\mathrm{BE}$ cannot be explained by differences in pulmonary ventilation.

\section{NORMAL V HOT HUMID CONDITIONS}

The concentration of $\mathrm{BE}$ in blood appeared to be slightly raised during mouth exposure to hot and humid, compared with "normal" chamber air. The increase may be partly explained by a raised pulmonary ventilation. The tendency towards higher blood concentrations in hot and humid conditions was more pronounced during the skin exposure (figure and table 1). This tendency was also reflected in increased percutaneous absorption rates of $\mathrm{BE}$. None of the differences between "normal" and hot humid climate conditions were, however, statistically significant.

\section{Discussion}

The blood concentrations of BE during exposure only by mouth in the present experiments (mean 2.9 $\mu \mathrm{mol} / 1$ during second hour) are 2.3 times lower than the concentrations found during whole body exposure $(7.4 \mu \mathrm{mol} / 1)$ in a previous study, ${ }^{1}$ when corrections are made for differences in exposure concentration $\left(2.0 v 0.85 \mathrm{mmol} / \mathrm{m}^{3}\right)$ and pulmonary ventilation ( $8.8 v 22.6 \mathrm{l} / \mathrm{min})$. The most probable explanation for this difference is that dermal uptake largely contributed to the internal dose of BE during the whole body exposure. This explanation is supported by the similar half lives of $\mathrm{BE}$ seen in the two studies. The values for apparent clearance and volume of distribution of $\mathrm{BE}$, which were calculated from the inhaled amount of BE in the whole body exposure study, may thus be underestimates by a factor of about two.

The apparent clearance of BE from blood during exposure by mouth was $3.9(3.3-5.0) 1 / \mathrm{min}$ in the present study. This value is much higher than the liver blood flow of about $1.6 \mathrm{l} / \mathrm{min}$ in a $70 \mathrm{~kg}$ man; thus extrahepatic metabolism of $\mathrm{BE}$ is suggested. The value is, however, in close agreement with previous estimates after intravenous bolus injections in guinea pigs, ${ }^{7}$ after correcting for differences in body surface area between the two species.

Apparent blood clearance values of about $1 \cdot 2 \mathrm{l} / \mathrm{min}$ obtained in the whole body exposure study were used to calculate percutaneous absorption rates of $\mathrm{BE}$ when the same subjects were later dermally exposed to neat $\mathrm{BE} .^{5}$ The present results suggest that the clearance values used, and thus the dermal uptake rates reported, may be underestimates by a factor of about two.

In our present study a tendency towards increased dermal uptake at raised air temperature and humidity was noted. The raised air humidity will result in hydration of the stratum corneum. Increased skin hydration is generally considered to have an absorption enhancing effect. ${ }^{89}$ Cellular proteins as well as the intercellular lipid matrix will be hydrated and lipids may have an increased disorganisation, thereby decreasing the barrier properties particularly towards hydrophilic, but also lipophilic, compounds. ${ }^{10}$ This effect was shown in an earlier study with guinea pigs, where the percutaneous absorption rate of $\mathrm{BE}$ diluted in water was even higher than that of neat BE. ${ }^{11}$ The low saturation concentration, low evaporation rate, and high affinity for water (table 2) suggest that $B E$ vapour in the surrounding air accumulates in the hydrated portion of the stratum corneum. Thus in the present experimental situa-

Table 2 Physicochemical properties and percutaneous absorption rates of neat glycol ethers (the values were rounded off)

\begin{tabular}{|c|c|c|c|c|}
\hline Glycol ether & $\begin{array}{l}\text { Water:air } \\
\text { partition } \\
\text { coefficient } \\
\text { at } 37^{\circ} \mathrm{C}^{18}\end{array}$ & $\begin{array}{l}\text { Saturation } \\
\text { concentration } \\
(\text { ppm)at } \\
25^{\circ} \mathrm{C}^{19}\end{array}$ & $\begin{array}{l}\text { Evaporation } \\
\text { rate relative } \\
\text { to butyl } \\
\text { acetate }^{20}\end{array}$ & $\begin{array}{l}\text { Percutaneous } \\
\text { absorption } \\
\text { rate } \\
\left(\mu \mathrm{mol} / \mathrm{min} / \mathrm{cm}^{2}\right)\end{array}$ \\
\hline $\begin{array}{l}\text { 2-Methoxyethanol } \\
\text { 2-Ethoxyethanol } \\
\text { 2-Butoxyethanol }\end{array}$ & $\begin{array}{r}35900 \\
23100 \\
7100\end{array}$ & $\begin{array}{r}12800 \\
7600 \\
930\end{array}$ & $\begin{array}{l}0.5 \\
0.3 \\
0.07\end{array}$ & \multirow{2}{*}{$\begin{array}{l}0.62^{\star} \\
0 \cdot 15^{\star} \\
0 \cdot 028^{\star} \\
0.007-0.096 \dagger \\
0 \cdot 22^{\star}\end{array}$} \\
\hline 1-Methoxy-2-propanol & 12300 & 15500 & $0 \cdot 7$ & \\
\hline
\end{tabular}

«Human skin in vitro. 4

†Human skin in vivo. 
tion, as well as in a hot and humid work situation, a steep concentration gradient that enhances percutaneous penetration may be expected. Other glycol ether vapours have similar characteristics (table 2) and one might therefore suspect that these would also easily penetrate the skin.

In one study ${ }^{12}$ a threefold increase in the percutaneous absorption of xylene vapour was seen in a subject with current atopic dermatitis, indicating an impaired barrier function. The mild skin disorders seen among the subjects in the present investigation are not believed to have influenced the barrier function of the skin.

From human or animal studies it has been estimated that the dermal uptake only accounts for between 0.1 and $10 \%$ of the total uptake of non-polar vapours of benzene, bromochloromethane, dibromomethane, halothane, hexane, isoflurane, mercury, perchloroethylene, styrene, toluene, 1,1, 1-trichloroethane, and xylene. ${ }^{12-17}$ From these studies one might assume that, in general, the contribution of dermal uptake to the total uptake of solvent vapours is of minor concern. Given the present results, such a generalised view may not be valid for $B E$ and other glycol ether vapours.

In conclusion, our present study indicates that the dermal uptake of $B E$ vapour from ambient air is appreciably higher than the respiratory uptake. As a consequence, a person exposed to $B E$ vapour may not be adequately protected by using a respiratory protection mask alone.

We are grateful to Professor J E Wahlberg for medical examinations and comments on the manuscript, and to Ms L Ernstgård, Ms E Gullstrand, and Ms S Johnsson for excellent technical assistance.

Requests for reprints to: Gunnar Johanson, Dr Med Sc, Division of Work and Environmental Physiology, National Institute of Occupational Health, S-171 84 Solna, Sweden.

1 Johanson G, Kronborg H, Näslund PH, Byfält Nordqvist $M$. Toxicokinetics of inhaled 2-butoxyethanol (ethylene glycol monobutyl ether) in man. Scand $J$ Work Environ Health 1986;12:594-602.

2 Groeseneken D, Veulemans H, Masschelein R. Respiratory uptake and elimination of ethylene glycol monoethyl ether after experimental human exposure. $\mathrm{Br} J$ Ind Med 1986; 43:544-9.

3 Groeseneken D, Veulemans H, Masschelein R, Van Vlem E. Experimental human exposure to ethylene glycol monomethyl ether. Int Arch Occup Environ Health 1989;61:243-7.

4 Dugard PH, Walker M, Mawdsley SJ, Scott RC. Absorption of some glycol ethers through human skin in vitro. Environ Health Perspect 1984;57:193-7.

5 Johanson G, Boman A, Dynesius B. Percutaneous absorption of 2-butoxyethanol in man. Scand J Work Environ Health 1988;14:101-9.

6 Dubois D, Dubois EF. Clinical calorimetry. 10. A formula to estimate the approximate surface area if height and weight be known. Arch Intern Med 1916;17:863-72.

7 Johanson G, Fernström P. Percutaneous uptake rate of 2butoxyethanol in the guinea pig. Scand $J W$ ork Environ Health 1986;12:499-503.

8 Dugard PH. Skin permeability theory in relation to measurements of percutaneous absorption in toxicology. In: Marzulli FN, Maibach HI, eds. Dermatotoxicology. Washington, DC: Hemisphere, 1987:95-120.

9 Bucks DA, Maibach HI, Guy RH. Occlusion does not uniformly enhance penetration in vivo. In: Bronaugh RI, Maibach HI, eds. Percutaneous absorption. Mechanisms-methodology-drug delivery. New York, NY: Marcel Dekker, 1989:77-93.

10 Goodman M, Barry BW. Action of penetration enhancers on human stratum corneum as assessed by differential scanning calorimetry. In: Bronaugh RL, Maibach HI, eds. Percutaneous absorption. Mechanisms-methodology-drug delivery. New York, NY: Marcel Dekker, 1989:567-93.

11 Johanson G, Fernström P. Influence of water on the percutaneous absorption of 2-butoxyethanol in guinea pigs. Scand J Work Environ Health 1988;14:95-100.

12 Riihimäki V, Pfäffli P. Percutaneous absorption of solvent vapors in man. Scand $J$ Work Environ Health 1978;4:73-85.

13 McDougal JN, Jepson GW, Clewell HJI, Andersen ME. Dermal absorption of dihalomethane vapors. Toxicol Appl Pharmacol 1985;79:150-8.

14 McDougal JN, Jepson GW, Clewell HJI, Gargas ML, Andersen ME. Dermal absorption of organic chemical vapors in rats and humans. Fundam Appl Toxicol 1990;14:299-308.

15 Hursh JB, Clarkson TW, Miles EF, Goldsmith LA. Percutaneous absorption of mercury vapor by man. Arch Environ Health 1989;44:120-7.

16 Tsuruta $H$. Skin absorption of organic solvent vapors in nude mice in vivo. Ind Health 1989;27:37-47.

17 Wieczorek H. Evaluation of low exposure to styrene. II. Dermal absorption of styrene vapours in humans under experimental conditions. Int Arch Occup Environ Health 1985;57:71-5.

18 Johanson G, Dynesius B. Liquid/air partition coefficients of six commonly used glycol ethers. Br J Ind Med 1988;45:561-4.

19 Rowe VK, Wolf MA. Derivatives of glycols. In: Clayton GD, Clayton FE, ed. Patty's industrial hygiene and toxicology. New York: John Wiley and Sons, 1982:3909-4052.

20 Smith RL. Review of glycol ether and glycol ether ester solvents used in the coating industry. Environ Health Perspect 1984; 57:1-4.

Accepted 4 March 1991 